\section{Radical rethink is needed on climate-change policy}

SIR - The irreconcilable differences between David S. Reay's Book Review of The Hot Topic (Nature 452, 31; 2008) and mine, expressed in Nature Reports Climate Change (see www.nature.com/climate/ 2008/0804/full/climate.2008.23.html), go to the heart of why there is now a crisis in climate policy. Reay seems to believe that agreement with a normative agenda precludes the need for rigorous evaluation of evidence or of proposed policy actions, and so falls into the same traps as Gabrielle Walker and David King, the authors whom he praises.

These authors have no doubt that the Kyoto Protocol is the road to follow. They consider that anyone, particularly an American, who doesn't agree is wrong and perhaps even corrupt.

However, the Kyoto approach is broken, as my colleague Steve Rayner and I have pointed out (Nature 449, 973-975; 2007). The 'bigger and better Kyoto' formula promoted by the authors - and by Al Gore, the European Union and the British Government - was defeated in Bali in December.

Instead, the geopolitical centre of gravity moved from Europe into the Pacific. There, four major powers will determine the future shape of global climate policy: China, India, Japan and the United States, supported by Canada and Australia (once that country recovers from the excitement of the symbolic act of 'signing Kyoto').

The framing concept for future climate policy must now shift, recognizing the failure of Kyoto to manage demand by imposing output targets. The reduction of energy intensity across all economies, including those of China and India, focusing first upon those primary sectors with the heaviest energy use, is emerging as the most robust replacement.

This approach not only preserves competitiveness but also has a demonstrated capacity to deliver results. It is now being promoted with increasing vigour outside Europe.

The reality is that we are at a tipping point for climate policy. Now is a moment where new ideas and new options arising from a radical rethink of the dismal record so far could have a dramatic and positive effect. Instead of welcoming such a discussion, the authors of The Hot Topic seem to wish to prevent it by continuing a tired political campaign for an approach that has not worked and cannot work.

Where climate change is concerned, it is not enough to identify good guys and bad guys - we must also be able to discern good policies from bad. The authors and reviewer of The Hot Topic conflate their judgements of the former with the latter. Gwyn Prins

Mackinder Centre for the Study of Long Wave Events, London School of Economics, Houghton Street, London WC2A 2AE, UK

\section{Comparing the legacies of Gauss, Pasteur and Darwin}

SIR - Kevin Padian's enthusiastic Essay on Charles Darwin ('Darwin's enduring legacy' Nature 451, 632-634; 2008) asks whether any single individual made so many lasting contributions to a broad area of science as Darwin did to biology. Let us remember that the nineteenth century also included Carl Friedrich Gauss, often called the greatest mathematician since antiquity, and Louis Pasteur, sometimes considered humanity's greatest benefactor because of his (and Robert Koch's) germ theory of disease.

It is a straightforward exercise to counter Padian's top ten darwinian topics (all of them evolution-oriented) with a much broader list for Gauss. He profoundly influenced modern life with his fundamental breakthroughs in statistics, algebra, analysis and other fields of mathematics - the 'queen of sciences'. His insights permeate all areas of science and engineering, including the theory of evolution.

Without Pasteur's revolution in medicine, many beacons of social and intellectual life would not have survived to formulate their thoughts. So, although Darwin was certainly one of the greatest, he had some even more influential contemporaries.

\section{Jürgen Schmidhuber}

IDSIA, Galleria 2, 6928 Manno, Switzerland, and Fakultät für Informatik, TU München, 85748 Garching bei München, Germany

\section{Spanish funds will finance Bilbao's spallation bid}

SIR - As the president of the executive commission of the proposed European Spallation Source (ESS) neutron-science facility in Bilbao, Spain, I appreciate the comments in your Editorial 'The big picture' (Nature 450, 586; 2007) about European endeavours to construct and finance the ESS. Although the commission acknowledges that there is a tendency in other countries to use European funds to finance such scientific projects, this does not apply in our case.

The joint bid by Spain and Hungary does not propose the use of European funds for this purpose. Our intention is simply to work together to facilitate approval for the construction of this important project, in the absence of specially allocated
European funds (see www.essbilbao.com). As a candidate host for the ESS, Bilbao depends exclusively on funds provided by the Spanish central government and the Basque government. These funds will provide sufficient core financial support to implement the project with a clear guarantee. Juan Urrutia

Executive Commission of ESS-Bilbao, Gran Vía 35, 48009 Bilbao, Spain

\section{Give south Indian authors their true names}

SIR - Your recent News Feature 'Identity crisis' (Nature 451, 766-767; 2008) reveals that many Chinese, Japanese and Korean researchers do not receive due credit for their work, owing to inconsistent abbreviation practices and journal requirements regarding names. Many other Asian scientists face similar problems.

We are three female postgraduate students of south Indian ancestry. Indians from the south traditionally do not have surnames. It is only when forced to comply with Western naming standards that they use their father's given name as a substitute. As a consequence, journal rules require them to publish research under the fathers' given names (with which we - Nalini, Jeevananthinee and Sujatha - also sign this Correspondence letter). Obviously, as young south Indian scientists making a contribution to science, we would prefer to be identified with our first names and not by our fathers' given names.

India produces more than 100,000 postdoctoral scientists every year (see Nature India at www.nature.com/nindia/about/ index.html). We believe that now is the time to introduce a consistent publication system that accommodates Indian names. The universal author-identification that uses contributor IDs, as discussed in your News Feature, is a good start. Such a system could be designed along the lines of the digital object identifier (doi) system used for journal articles. That could be followed by changes to reference rulings in journals to allow for citation of papers with single-name authors who are linked to a contributor ID.

We hope that all of science will take note of the extent of the Asian identity crisis in publishing and will work towards creating a universal system of authorship.

Nalini Puniamoorthy, Jeevananthinee Jeevanandam, Sujatha Narayanan Kutty Department of Biological Sciences, National University of Singapore, 14 Science Drive 4, Singapore 117543, Singapore

Contributions may be submitted to correspondence@nature.com.We also welcome comments and debate at Nautilus (http://blogs.nature.com/nautilus). 